\title{
Design and Development of Small Electric Vehicle using MATLAB/Simulink
}

\author{
Bambang Sri Kaloko \\ Dept. of Elect. Eng., \\ University of Jember, Post- \\ graduate student in Institut \\ of Technology 10 \\ Nopember, Indonesia
}

\author{
Soebagio \\ Dept. of Elect. Eng., Institut \\ of Technology 10 \\ Nopember, Indonesia
}

\author{
Mauridhi Hery Purnomo \\ Dept. of Elect. Eng., Institut \\ of Technology 10 \\ Nopember, Indonesia
}

\begin{abstract}
The issue of the depletion of oil reserves in the world, and the problem of air pollution produced by motor vehicles, motivate many researchers to seek alternative energy sources to propel the vehicle. One promising way is to replace combustion motor with an electric motor, which is known as an electric vehicle. First stages of this research is to model the flow of power in the electric vehicle energy system to obtain its characteristics. Power flow efficiency in electric vehicle is very important because this type of vehicle is highly dependent on the limited electrical energy supplied by a battery. Therefore it should be managed properly. This study is to look into the power flow calculation so that the amount of electrical energy is in accordance with the needs of electric vehicle. The design of small electric vehicle model using MATLAB/Simulink software is to get the best power flow response to the electric vehicle energy system.
\end{abstract}

\section{Keywords}

Electric vehicle, power flow, state of charge, Simulink

\section{INTRODUCTION}

The indicators of success of development characterized by high levels of population mobility. To increase mobility services required a means of transportation. One of the means of transportation used in the cities and villages is a vehicle. In Indonesia, the vehicle is used mostly with oil fueled. Vehicles with fuel oil is grow in line with lower world oil prices at the time and too much supply of fuel oil [3]. Consumption of fuel for vehicles is more increasing. More than half of world energy consumption is used for transportation. Figure 1 illustrates the differences are striking between fuel demand and world oil production after the year 2020 [8].

Increased consumption of fuel oil to fuel the vehicle affect fuel supplies are running low [8],[11]. Besides, the use of fuel oil on the vehicles produce exhaust gases that potentially pollute the environment. Flue gases produced by vehicles consist of $18 \%$ solid particles, $27 \%$ mixture of volatiles (comprising $28 \% \mathrm{~Pb}$, $32 \% \mathrm{NO}$ and $62 \% \mathrm{CO}$ ) and $\mathrm{CO} 2$ by $25 \%$ [2].

Another deficiency of this type of vehicle is the noise level is high enough. Air pollution also impacts on the environment [1] and human health [5]. Of these problems need to be a change in energy source from fuel oil to electricity as a source of power driving a vehicle.
Human effort in order to reduce dependence on petroleum fuels and environmental pollution is to make electric vehicle [3],[6],[12]. The main components of the electric vehicle is an electric motor as drive systems, electrical energy sources, control systems as a central control, and power converter as a device that converts electrical energy source with variable needs of the electric vehicle by switching devices. Meanwhile electric vehicles generally use a battery as its main energy source [2],[3],[6]. But the batteries on electric vehicles have a weakness that has the capacity and service life is limited so that necessary arrangements for charging batteries do not work hard. Power flow model of electric vehicle energy system is needed to obtain the energy needed by an electric vehicle that can determine the required battery capacity.

The experiments to determine the capacity of the battery when the battery in working condition also has been done [10]. While the development of hybrid electric vehicle with energy from the battery and flywheel also been conducted[7]. Flywheel energy is used as an alternative if the vehicle is in acceleration phase. Through this flywheel as well as the remaining energy is used for regenerative braking is stored in the battery. Dynamic model of a complete electric vehicle consists of controllers, inverters, traction motors and batteries and braking have also been developed [9]. The model was developed with model Matlab/Simulink (Mathworks). The prediction model of electrical energy in electric vehicle with MATLAB / Simulink was also developed with statistical methods [4].

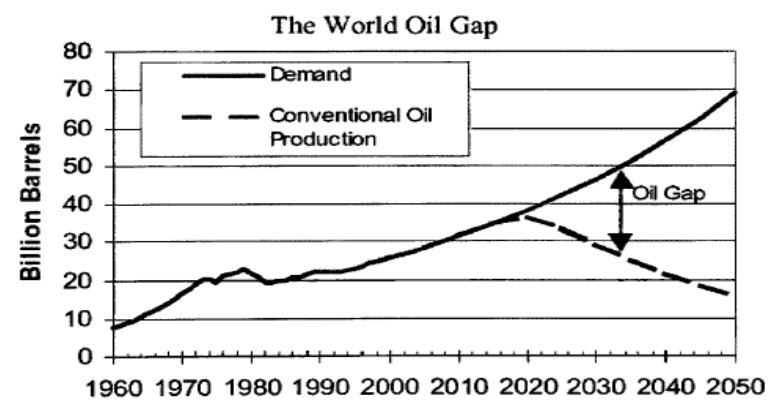

Fig 1: World oil demand by 2050 [8].

We developed an electric vehicle adapted to urban conditions in Indonesia which densely populated and narrow streets. This type of vehicle is expected to be solution for urban transportation later. The electric vehicle which we developed can be seen in Figure 2. 


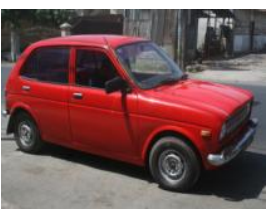

(a)

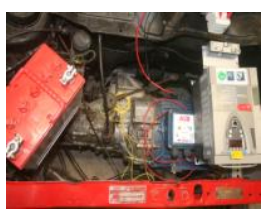

(b)

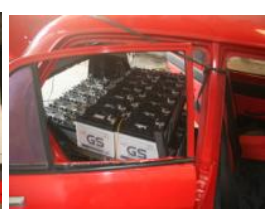

(c)
Fig 2: The development of electric vehicle
(a) An EV
(b) System of EV
(c) A unit of battery

\section{MATERIAL AND METHODS}

\subsection{Material}

The materials used in this work were a Lead acid battery type 46B24L produced by PT. GS Battery Indonesia, a unit of Honda life, an induction machine and a unit of inverter. In the implementation of electric vehicles that use parameters should be tested. From the data obtained by physical examination including specification electric vehicle and battery data 46B24L type as shown in table 1 and table 2 below:

Table 1. The specifications of electric vehicle in this study

\begin{tabular}{|c|c|}
\hline Electric Vehicle Spesification & Size \\
\hline Weight $(\mathrm{kg})$ & 900 \\
\hline Friction coefficient & 0,19 \\
\hline Rotary coefficient & 0,0048 \\
\hline Max speed $(\mathrm{km} / \mathrm{jam})$ & 20 \\
\hline Acceleration $(\mathrm{km} / \mathrm{h} ; \mathrm{s})$ & $0 \rightarrow 60 ; 8,0$ \\
\hline Mileage $(\mathrm{km})$ & 60 \\
\hline Battery type & Pb/lead acid \\
\hline Battery voltage $(\mathrm{Volt})$ & 500 \\
\hline Motor capacity $(\mathrm{kWh})$ & 5,5 \\
\hline Converter type & IGBT inverter \\
\hline
\end{tabular}

Table 2. Physical data type of battery 46B24L

\begin{tabular}{|c|c|}
\hline Battery Type & Size \\
\hline Dimension $(\mathrm{mm}) \mathrm{t} \times 1 \times \mathrm{p}$ & $227 \times 129 \times 238$ \\
\hline Capacity [Ah] & 36 \\
\hline Discharge max [A] & 150 \\
\hline Weight $(\mathrm{kg})$ & 12,5 \\
\hline
\end{tabular}

\subsection{Instruments}

Mathematical Laboratory (Matlab) version R2008b (developed by MathWorks, Natick, Massachusetts) was employed to perform the simulation procedures and development of mathematical computing. All computational simulations were performed on a Window machine with Intel Dual Core $2 \mathrm{GHz}$ as the processors and $1 \mathrm{~GB}$ of RAM.

\subsection{Proposed Method}

The electric vehicle used in this research is a form of development of small car that suitable for urban areas in Indonesia. Vehicles designed in such a way as to be electric vehicles with parts such as induction machine as the prime mover, the inverter as a media liaison between dc source with induction machines, and battery as an energy source can be seen in Figure 3. The model is designed by using the program Simulink/Matlab.

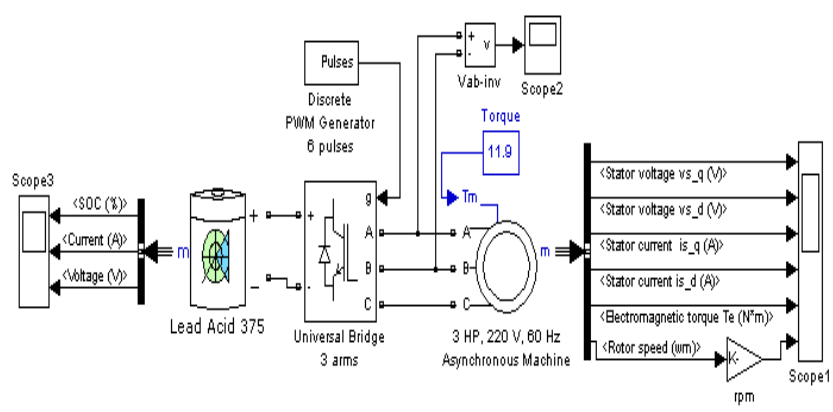

Fig 3: The model of electric vehicle in this study.

Induction motor is used as the driver has many advantages of robust, cheaper, widely used for electric driving with constant velocity, large inertia, no require routine maintenance. Induction motor as the driving has been modeled in qdn coordinates. This model more flexible than conventional models. Because, the model is possible to operates with a non sinusoidal voltage, even for conditions of non symmetrical source, the model can still be analyzed.

The battery which used as energy source are lead acid batteries type, they often found in the market and the relatively affordable price. This is one major factor why should this type of battery selected. Besides, this type of battery can be used for engine starting process that requires a fairly high currents. The output of this battery is a dc voltage/current, while the motor of an electric vehicle using an induction motor, then the power converter is required as the power supply to the induction motor. The power converter technology which used in this model is the PWM converter. 


\section{RESULT AND DISCUSSION}

\subsection{Tractive Effort Modelling}

The initial testing is conducted in accordance with the scenario. Analysis of electric vehicle is required to get the suitable size of the induction motor and battery source. First step is the modeling to make an equation of tractive effort to determine how much load on the electric vehicle to a flat road conditions. The tractive effort on electric vehicle include rolling resistance force, aerodynamic drag, hill climbing force and acceleration force should be studied further.The rolling resistance force is thrust into the front of the electric vehicle. This is equal to the transmitting wheel to be through a street like Figure 4. It is proportional to vehicle weight, the equation is:

$$
F_{r r}=\mu_{r r} m g
$$

where $F_{r r}$ is the rolling resistance force, $m$ is mass of vehicle, $g$ is the gravity and $\mu \mathrm{rr}$ is the coefficient of rolling resistance.

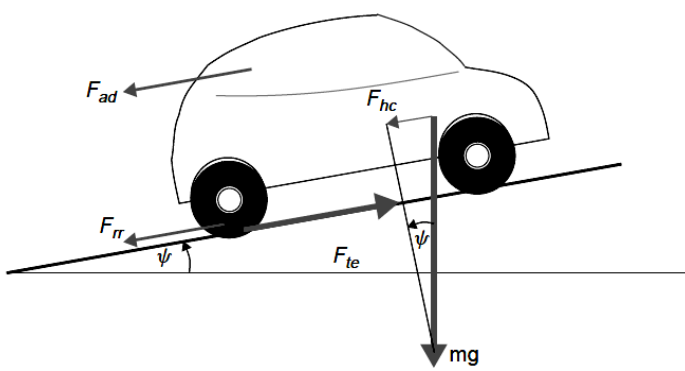

Fig 4: The forces acting on a vehicle moving [6].

Aerodynamic drag is the force on the vehicle that caused by the vehicle aerodynamic. This force is determined by the shape of the surface of the vehicle $(A)$, coefficient of form $\left(C_{d}\right)$, velocity (v) and air density $(\rho)$. The formula for this component is:

$$
F_{a d}=\frac{1}{2} \rho A C_{d} v^{2}
$$

Hill climbing force is the force on the vehicle to move up or move upward with a slope. By simple resolution of force we see that:

$$
F_{h c}=m g \sin (\psi)
$$

where $\Psi$ is the slope.

Acceleration force is the force required to increase the speed of the vehicle. If the linear acceleration of the vehicle according to Newton's second law is:

$$
F_{l a}=m a
$$

The vehicle moves with angular speed then the angular acceleration is required. Angular acceleration force is the force required by the wheels to make angular acceleration $\left(F_{\omega a}\right)$, as follow:

$$
F_{\omega a}=I \frac{G^{2}}{r^{2}} a
$$

where $\mathrm{I}$ is the moment of inertia, $\mathrm{G}$ is gear ratio, $\mathrm{r}$ is the radius of the tyre.

The total tractive effort is the sum of rolling resistance force, aerodynamic drag, hill climbing force, linear acceleration forces and angular acceleration force as follow:

$$
F_{t e}=F_{r r}+F_{a d}+F_{h c}+F_{l a}+F_{\omega a}
$$

The estimated of energy is required to be determine the battery capacity according to need. The needed energy of electric vehicle is:

$$
P_{t e}=F_{t e} x v
$$

where $v$ is the speed of vehicle.

From equation 1-7 we can be made a model using the software program MATLAB/Simulink that can be represent a vehicle. The input is needed from the model of acceleration, speed and slope of road while the output of motor and currents as shown in Figure 5. Based on data in table 1, it would be require a force of $527.6 \mathrm{~N}$ to move the prototype electric vehicle models.

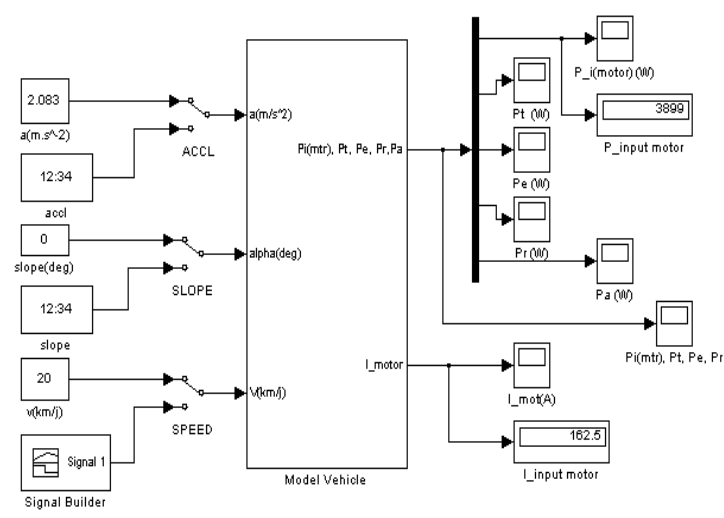

Fig 5: The power flow of electric vehicle model.

With reference to the testing a maximum speed of $20 \mathrm{~km} / \mathrm{h}$ in 8 seconds, if an electric vehicle with $900 \mathrm{~kg}$ total mass, friction coefficient of 0.19 , the air density of 1.25 and aerodynamic factors of 0.75 , the surface area of vehicles $1.49 \mathrm{~m}^{2}$, the gear ratio factor $\mathrm{G}$, at 2 , wheel radius of $0.3 \mathrm{~m}$, and maximum power 
efficiency of 0.77 then the induction machine is needed 3899 Watts.

From equation 7 obtained a significant relationship between the power required by the induction machine as a driving electric vehicles with lead acid batteries as the source. Effective energy than lead acid batteries used in this study is $21060 \mathrm{kWs}$. With the assumption of supreme power that is absorbed by the induction machine to drive an electric vehicle by $3889 \mathrm{~W}$, the battery can provide energy for 5401 seconds or about 1 hour 30 minutes 1.38 seconds.

\subsection{Electric Vehicle Acceleration Modelling}

The acceleration of an electric vehicle is a key performance indicator, though there is no standard measure used. Typically the time to accelerate from standstill to move will be given. The nearest to such a standard for electric vehicles are the $0-30 \mathrm{kph}$, though these times are not given for all vehicles. Such acceleration figures are found from simulation of real electric vehicles. The electric vehicles performance simulations are carried out at maximum torque.

The maximum torque of an electric motor is a fairly simple function of angular speed. In most cases, at low speeds, the maximum torque is a constant, until the motor speed reaches a critical value $\omega_{c}$ after which the torque falls, nevertheless the power remains constant. Meanwhile the angular velocity of the motor depends on the gear ratio $\mathrm{G}$ and the radius of the drive wheel $r$, so that :

$$
v<\frac{r}{G} \omega_{c} \text { then } T=T_{\max }
$$

After the starting phase is passed, then either the power is constant, and we have the torque is:

$$
T=T_{\max } \frac{r \cdot \omega_{c}}{G v}
$$

We can combine equation $6,8,9$ in order to find the acceleration of an electric vehicle is:

$$
\frac{d v}{d t}=\frac{\eta_{g} r^{2}}{\eta_{g} r^{2} m+I G^{2}}\left(\frac{G T}{r}-\mu_{r r} m g-\frac{1}{2} \rho A C_{d} v^{2}-m g \sin (\psi)\right)
$$

Provided that all the constants are known, or can reasonably be estimated, this is a very straightforward first-order differential equation to find the acceleration of an electric vehicle. The model simulation of acceleration is shown in Figure 6.

These values from table 1 can now be put into equation 10 then the model become:

$$
\begin{aligned}
& v_{n+1}=v_{n}+\partial t\left(3.11-0.000113 v_{n}^{2}\right. \\
& v_{n+1}=v_{n}+\partial t\left(\frac{62.1}{v_{n}}-0.046-0.000113 v_{n}^{2}\right)
\end{aligned}
$$

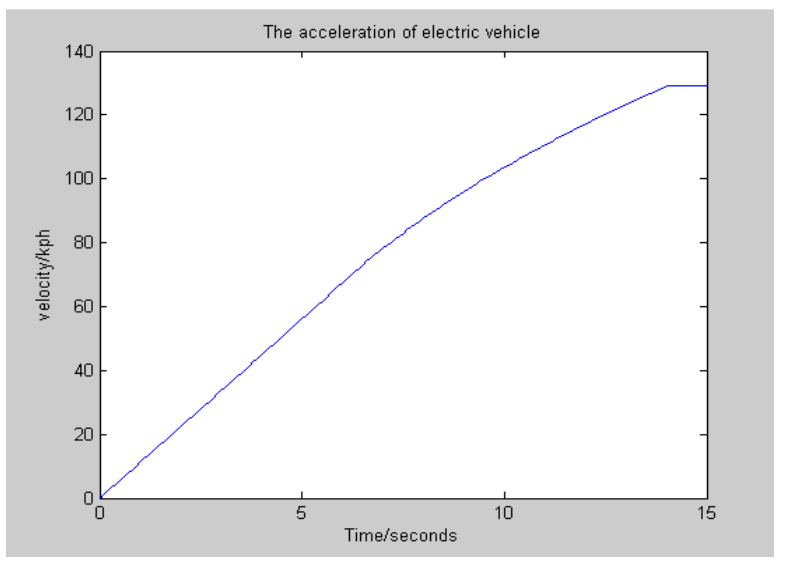

Fig 6: Simulasion of acceleration of electric vehicle model.

\subsection{Electric Vehicle System Modelling}

The model that proposed in Figure 3 is to get a performance of the electric vehicle. The model uses lead acid batteries 375 Volt, PWM inverter and three phase induction machine 220 Volt, 60 $\mathrm{Hz}$. The simulation of electric vehicle system modeling is shown in Figure 7.

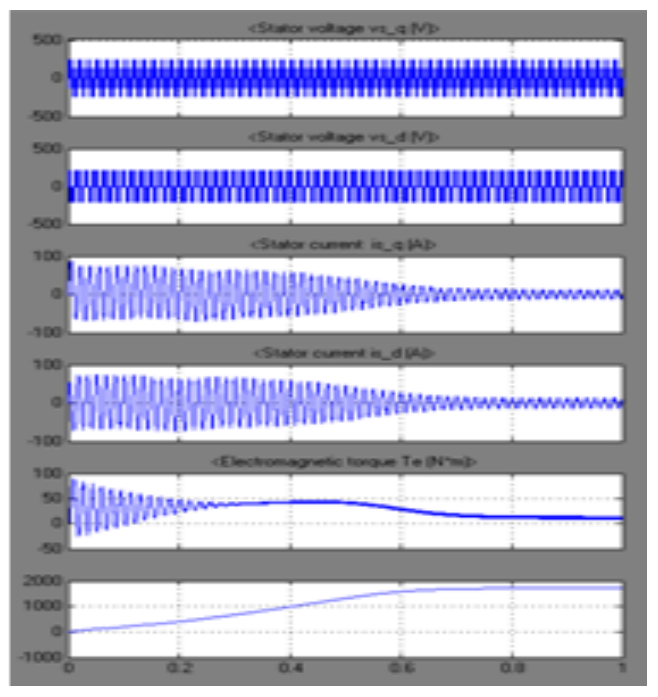

Fig 7: Simulasion of electric vehicle system model.

The simulations above to find out the performance of electric vehicle in starting conditions and running with constant speed. 


\section{CONCLUSION}

Modeling of electric vehicle system makes it easy to determine how much battery capacity required by an electric vehicle with certain specifications to achieve a certain distance as well. This model can be used to estimate how long the battery can be used in electric vehicles. The model can also be used to determine the performance of electric vehicle such as the starting process or running with constant speed

\section{ACKNOWLEDGMENTS}

This study was supported by post-graduate grant of Directorate General of Higher Education Republic of Indonesia through competitive grant with contract number 0172.0/023$04.2 / \mathrm{XV} / 2010$. I would like to express my thanks to everyone who helped me faithfully to finish the job. I would also like to thank the reviewers who gave very useful suggestions which help me improve the quality of research. I thank to the staff of the IJCA, who gave very valuable guidance in preparing the manuscript of my research.

\section{REFERENCES}

[1] Bernstein, L., Intergovernmental Pa-nel on Climate Change Fourth Assessment Report Climate Change 2007: Synthesis Report Summary for Policymakers, A-vailable Jan. 2008: www.ipcc.ch

[2] Dhameja, S., 2002, Electric Vehicle Battery Systems, Newnes, Uni-ted Stated.

[3] Husain, I., 2003, Electric and Hybrid Vehicles Design Fundamentals, Pertama, CRC Press, United Stated.

[4] Kim, S., Chung, S., Shin, W., Lee, J., A study of predicting model of an electrical energy balance for a conventional vehicle, Procee-dings of the 17th World Con-gress The International Federa-tion of Automatic Control Seoul, Korea, July 6-11, 2008.

[5] Kunzli, N., Public-Health Impact of Outdoor and TrafficRelated Air Pollution: A European Assess-ment, The Lancet, Vol. 356, Number 9232, September 2000, pp. 795 801.

[6] Larminie, J., Lowry, J., 2003, Electric Vehicle Technology Explained, John Wiley \& Son.

[7] Lustenader, E. L., Guess, R. H., Richter, Turnbull, F. G., De-velopment of a Hybrid Flywheel /Battery Drive System for Elec-tric Vehicle Applications, IEEE Transactions on Vehicular Tech-nology, Vol. VT-26, May 1977, pp.135143.

[8] Patterson, P., Quantifying the Fuel Use and GHG Reduction Poten-tial of EVs and HEVs, Available April 26, 2002, http://www.ott. doe.gov/pdfs/evs17 .pdf
[9] Powell, B. K., Bailey, K. E., Cikanek, S. R., Dynamic Modeling and Control of Hybrid Electric Ve-hicle Powertrain Systems, IEEE Control Systems. October 1998.

[10] Septimu, M., Liviu, T., Behavior of the Lead Acid Battery after the Rest Period, WSEAS TRAN-SACTIONS on POWER SYS-TEMS, Issue 3, Volume 3, March 2008.

[11] Wood, J. H., Long, G. R., More-house, D. F., Long Term World Oil Supply Scenarios: The Future Is Neither as Bleak or Rosy as Some Assert, US De-partment of Energy, 2004. Ava-ilable Jan. 2008: http://www.eia. doe.gov/pub/oil_gas/petroleum/feature_articles/2004/world oilsupply/oilsupply04.html

[12] Ying, S., Ding, S., Yang, J., Hung, R., Electrochemistry Theorem Ba-sed State-of-Charge Estimation of the Lead Acid Batteries for Electric Vehicles, WSEAS Tran-sactions on Systems, Issue 10, Volume 7, October 2008, pp.10-921103.

\section{AUTHOR PROFILE}

Bambang Sri Kaloko received B.Eng degree from Electrical Engineering Institute of Technology Bandung, Bandung Indonesia (1998). M.Eng degree from Electrical Engineering Institute of Technology Bandung, Bandung Indonesia (2002). Post-graduate student in Electrical Engineering, in Institute of Technology Sepuluh Nopember Surabaya-Indonesia (2007now). Some papers were published in Journals and seminars by colaboration with Prof. M. H. Purnomo and Prof Soebagio.

Soebagio received B.Eng degree from Electrical Engineering Institute of Technology Bandung, Bandung Indonesia. M.Eng and Ph.D from University of Wisconsin, USA. Now, he is a professor in electric drive system in Department of Electrical Engineering, Institute of Technology Sepuluh Nopember Surabaya Indonesia. Prof. Soebagio is a member of Indonesian Institution of Engineers.

Mauridhi Hery Purnomo received B.S. degree from Electrical Engineering, in Institute of Technology Sepuluh Nopember Surabaya-Indonesia. Master and Ph.D from Osaka City University, Osaka, Japan.Now, he is a professor in intelligence system in Department of Electrical Engineering, Institute of Technology Sepuluh Nopember Surabaya Indonesia. Prof. Mauridhi Hery Purnomo is a member of Indonesian Institution of Engineers. 